\title{
СОВРЕМЕННЫЕ МЕТОДЫ ХИРУРГИЧЕСКОГО ЛЕЧЕНИЯ ПАХОВОЙ ГРЫЖИ
}

\section{MODERN METHODS OF SURGICAL TREATMENT OF INGUINAL HERNIA}

\author{
A. Protasov \\ Mekhaeel Shehata Fakhry Mekhaeel \\ A. Dzhabiev \\ A. Kulakova \\ E. Ibragimov
}

Summary. The article is devoted to modern methods of surgical treatment of inguinal hernia. The urgency of the problem is shown due to the high prevalence of the disease, the high risk of relapses after surgical treatment. The main methods of surgical treatment of inguinal hernias in modern herniology are described. A comparative analysis of the effectiveness of endoscopic inguinal hernia repair using transabdominal preperitoneal (TARP) and transabdominal extraperitoneal plastic (TER) was performed. The results of the postoperative period are shown, depending on the mesh endoprosthesis used. The advantages and disadvantages of the open and laparoscopic method of hernioplasty are revealed. The effectiveness of the use of tension-free seamless methods of open plastic surgery of inguinal hernia is shown. Modern methods of video endosurgical hernioplasty are described. It is concluded that the variety of existing methods of surgical treatment of inguinal hernias causes the problem of choosing effective methods of surgical intervention, taking into account the risks of chronic pain syndrome and the development of inguinal hernia recurrence.

Keywords: inguinal hernia, endoscopic hernioplasty, laparoscopic hernioplasty, mesh endoprosthesis.

\author{
Протасов Андрей Витальевич \\ Д.м.н. профессор, Российский университет Дружбы \\ Народов \\ andrei.protasov@bk.ru \\ Мекхаеэль Шехата Факхри Мекхаеэль \\ Аспирант, Российский университет Дружбы \\ Народов \\ Mekhaeel60@yahoo.com \\ Джабиев Аяз Айдын оглы \\ Аспирант, Российский университет Дружбы \\ Народов \\ Dzhabievayaz.3@mail.ru \\ Кулакова Анна Леонидовна \\ К.м.н., Ассистент, Российский университет Дружбы \\ Народов \\ Sable7@bk.ru \\ ибрагимов Эльчин Сахават оглы \\ Аспирант, Российский университет Дружбы \\ Народов \\ Refaro@mail.ru
}

Аннотация. Статья посвящена современным методам хирургического лечения паховой грыжи. Показана актуальность проблемы по причине высокой распространенности заболевания, высокого риска рецидивов после хирургического лечения. Описаны основные методы хирургического лечения паховых грыж в современной герниологии. Проведен сравнительный анализ результативности эндоскопической пластики паховых грыж с использованием трансабдоминальной преперитонеальной (ТАРP) и трансабдоминальной экстраперитонеальной пластик (ТЕР). Показаны результаты послеоперационного периода в зависимости от используемого сетчатого эндопротеза. Раскрыты преимущества и недостатки открытого и лапароскопического метода герниопластики. Показана эффективность использования безнатяжных бесшовных методов открытой пластики паховой грыжи. Описаны современные методики видеоэндохирургической герниопластики. Сделан вывод о том, что многообразие существующих методов хирургического лечения паховых грыж обуславливает проблему выбора эффективных методик оперативного вмешательства с учетом рисков хронического болевого синдрома и развития рецидива паховой грыжи.

Ключевые слова: паховая грыжа, эндоскопическая герниопластика, лапароскопических герниопластика, сетчатый эндопротез.

предбрюшинной жировой клетчатки через грыжевой дефект в паховой области» [6, с. 8]. Распространенность паховых грыж среди населения, согласно статистическим данным ВО3, составляет около 3-6\%, причем ее распространенность наиболее высока среди лиц 
мужского пола, составляющая 6-7\% случаев, в отличие от распространенности среди женщин, которая отмечается в 2,5\% случаев. Паховые грыжи по частоте встречаемости занимают первое место среди всех видов грыж и составляют 75-80\% [4; 6]. Актуальность проблемы современных методов хирургического лечения паховых грыж обусловлена и достаточно высоким процентом рецидивов после хирургического лечения, которые достигает 10\% случаев при первичных и до $30 \%$ случаев при повторных операциях, снижение которых связано с внедрением новых методов хирургического лечения [6].

Основными способами хирургического лечения паховых грыж в современной герниологии являются открытая операция с пластикой местными тканями, открытая протезирующая и эндоскопическая протезирующая пластика с применением сетчатого эндопротеза. Открытая пластика паховых грыж с использованием сетки проводится посредством ряда способов хирургического лечения, показавших свою эффективность, к которым относятся «способы, при которых семенной канатик располагается под апоневрозом наружной косой мышцы живота; способы, при которых семенной канатик находится в подкожной клетчатке, а листки апоневроза сшиваются под семенным канатиком» [6, с. 22].

Эндоскопическая пластика паховых грыж, в свою очередь, проводится с использованием трансабдоминальной преперитонеальной (ТАРР) и трансабдоминальной экстраперитонеальной пластики (ТЕР). Каждый из методов обладает своими преимуществами. К преимуществам ТАРР относятся, как отмечает А.А. Поляков на основе анализа данных клинических исследований, «более привычный вид на грыжевой дефект со стороны брюшной полости с точной визуализацией основных ориентиров, возможность визуализации контрлатеральной грыжи без дополнительного рассечения и мобилизации тканей, выявление грыжи спортсмена, визуализация оккультных грыж; возможность выполнения симультанных вмешательств на органах брюшной полости» [5, с. 34]. К негативным последствиям метода ТАРР относятся «риски травмы органов брюшной полости, развития спаечного процесса и кишечной непроходимости, ущемления кишки в дефекте неадекватно ушитой брюшины, а также возможность формирования троакарных грыж» [5, с. 34-35]. Преимуществами метода TEP, в отличие от ТАРР, являются «меньший риск внутрибрюшной травмы, меньшее количество спаек в животе, отсутствие необходимости выполнять и ушивать разрез брюшины» [5, с. 35].

Представленные в исследовании Ш.И. Ахмедова результаты клинических исследований позволяют сделать обоснованный выбор оптимального для каждо- го пациента метода лечения паховых грыж на основе сравнительного анализа преимуществ и недостатков данных методов хирургического лечения грыж. Так, результаты протезирующих герниопластик паховых грыж при ТЕР, в отличие от ТАРР, показали менее выраженный болевой синдром в послеоперационном периоде и меньшее количество осложнений. Основным преимуществом метода ТАРР является возможность выполнения грыжессечения при любых формах грыж и диагностической лапароскопии брюшной полости, а также меньший риск возникновения рецидива, по сравнению с методом ТЕР и открытой герниопластики [1].

С целью повышения результативности хирургического лечения паховых грыж, как за рубежом, так и в отечественной хирургии практически ежегодно публикуется обзор рандомизированных контролируемых клинических исследований, в котором проводится сравнительный анализ послеоперационного периода после лапароскопических герниопластик в зависимости от используемого сетчатого эндопротеза новой легкой или традиционной сеткой. Согласно результатам, в послеоперационном периоде оба варианта сетчатого эндопротеза показали практически одинаковый результат. Хорошо зарекомендовали себя биологические протезы, сетчатые эндопротезы, пропитанные антибактериальным препаратом, самофиксирующиеся сетки, сетки с памятью формы пахового промежутка 3D, однако они не нашли широкого применения по причине высокой стоимости [1]. В исследовании А.Б. Бабурина показано, что использование эндопротезов на основе поливинилиденфторида, реперена при выполнении методов пластики позволяет сохранить репродуктивную функцию у мужчин молодого возраста. В клиническую практику внедрены новые способы пластики при паховых грыжах, которые позволяют изолировать семенной канатик от эндопротеза, что способствует улучшению ближайших и отдаленных результатов лечения пациентов с данной патологией за счет снижения количества рецидивов и сохранения репродуктивной функции у оперированных мужчин молодого возраста [2]. Хирургическое лечение паховых грыж с использованием бесфиксационной ТАРР-пластики, согласно клиническим данным, полученным А.В. Кошкиной, характеризуется низким болевым синдромом, в отличие от пластики с фиксацией эндопротеза герниостеплером. При этом ранний послеоперационный период бесфиксационной ТАРР-пластики не сопровождается осложнениями по сравнению с ТАРР- пластикой с фиксацией эндопротеза герниостеплером [4].

В хирургическом лечении паховых грыж в настоящее время также нет однозначного мнения о преимуществах открытого или лапароскопического метода герниопластики. В последние годы применение 
безнатяжных бесшовных методов открытой пластики паховой грыжи доказало свою эффективность, в отличие от методов эндоскопической герниопластики. При лечении паховых грыж методом открытой герниопластики используется самофиксирующийся сетчатый имплант или фиксация его клеевым компонентом на основе цианаклитатов, что снижает травматичность хирургического вмешательства и сроки реабилитации пациента. Герниопластика открытым методом имеет ряд преимуществ, к которым относятся возможность выполнения ее под местным обезболиванием, что уменьшает риск повреждения органов брюшной полости, в отличие от эндоскопического вмешательства, при котором повреждение брюшины является неизбежным. Не менее важным аспектом является экономические затраты на эндоскопическое оборудование, стоимость сетчатых имплантов и обучение медицинского персонала, которое выше, чем при организации подобной операции открытым методом [3].

Лапароскопическая пластика, по мнению ее сторонников, также имеет преимущества, к которым относятся низкий уровень послеоперационной боли, ранняя реабилитация пациентов, минимальный риск развития рецидивов и косметический эффект $[1 ; 5]$. Интерес представляют современные методики видеоэндохирургической герниопластики. В исследовании
А.А. Полякова на основе комплексного сравнительного анализа непосредственных и отдаленных результатов после видеоэндохирургической ТАРР и ТЕР паховой герниопластики в зависимости от способа позиционирования сетчатых имплантатов: инвазивного - редуцированного степлерного, неинвазивного клеевого, бесфиксационного - вакуумного, доказаны преимущества неинвазивной методики, к которым относятся уменьшение болевого синдрома в раннем послеоперационном периоде, а при использовании редуцированного степлерного - минимизация риска развития хронического болевого синдрома в отдаленном периоде [5].

Итак, многообразие существующих методов хирургического лечения паховых грыж обуславливает проблему выбора эффективных методов оперативного вмешательства, обеспечивающих результативность лечения и профилактику рецидива паховых грыж. Современные методы хирургического лечения паховых грыж имеют свои преимущества и недостатки. Поэтому имеет место проблема выбора оптимальной методики хирургического вмешательства и способа позиционирования сетчатого имплантата для каждого отдельного пациента с учетом анатомических и технических рисков развития рецидива грыжи и хронического болевого синдрома.

\section{ЛИТЕРАТУРА}

1. Ахмедов Ш.И. Сравнительная характеристика современных методов герниопластики ТАРР (трансабдоминальная преперитонеальная) и ТЕР (тотальная экстраперитонеальная) при лечении паховых грыж: дис. ... канд. мед. наук: 14.01.17. — Рязань, 2016. — 114 с.

2. Бабурин А.Б. Выбор метода пластики при паховых грыжах у мужчин молодого возраста: дис. ... канд. мед. наук: 14.01.17.— Нижний, 2014.— 108 c.

3. Волков А.М. Методология оперативного лечения паховой грыжи (краткий обзор литературы) // Вестник новых медицинских технологий. Электронное издание. 2016. № 4. Режим доступа: http://www.medtsu.tula.ru/VNMT/Bulletin/E2016-4/8-8.pdf.

4. Кошкина А.В. Лапароскопическая бесфиксационная аллогерниопластика в лечении паховых грыж: дис. ... канд. мед. наук: 14.01.17.— Рязань, 2020. - 138 c.

5. Поляков А.А. Видеоэндохирургические подходы к аллогерниопластике при паховых грыжах: дис. ... канд. мед. наук: 14.01.17.— Волгоград, 2020.$148 \mathrm{c}$.

6. Шабунин А.В. Паховые грыжи. Современные принципы диагностики и лечения: учебная лекция/ А.В. Шабунин, Г.С. Михайлянц, Д.В. Матвеев, В.А. Иванюгин; ГБоУ дПо «Российская медицинская академия последипломного образования».— М.: ГБоУ дПо РМАП0, 2014. — 52с.

( Протасов Андрей Витальевич ( andrei.protasov@bk.ru ), Мекхаеэль Шехата Факхри Мекхаеэль ( Mekhaeel60@yahoo.com ), Джабиев Аяз Айдын оглы ( Dzhabievayaz.3@mail.ru ), Кулакова Анна Леонидовна ( Sable7@bk.ru ),

Ибрагимов Эльчин Сахават оглы ( Refaro@mail.ru).

Журнал «Современная наука: актуальные проблемы теории и практики» 